\title{
Fluorescent Organic Nanoparticles of Benzofuran-Naphthyridine Linked \\ Molecules: Formation and Fluorescence Enhancement in Aqueous Media
}

\author{
Yeh-Yang Sun, ${ }^{\dagger}$ Jen-Hai Liao, ${ }^{\dagger}$ Jim-Min Fang, ${ }^{,},+, \ddagger$ Pi-Tai Chou, ${ }^{\dagger}$ \\ Ching-Hsing Shen, $\$$ Chih-Wei Hsu, $\$$ and Li-Chyong Chen $\$$ \\ Department of Chemistry, National Taiwan University, Taipei 106, Taiwan, Genomics \\ Research Center, Academia Sinica, Taipei 115, Taiwan, and The Center for Condensed \\ Matter Sciences, National Taiwan University, Taipei 106, Taiwan
}

jmfang@ntu.edu.tw

Received May 26, 2006
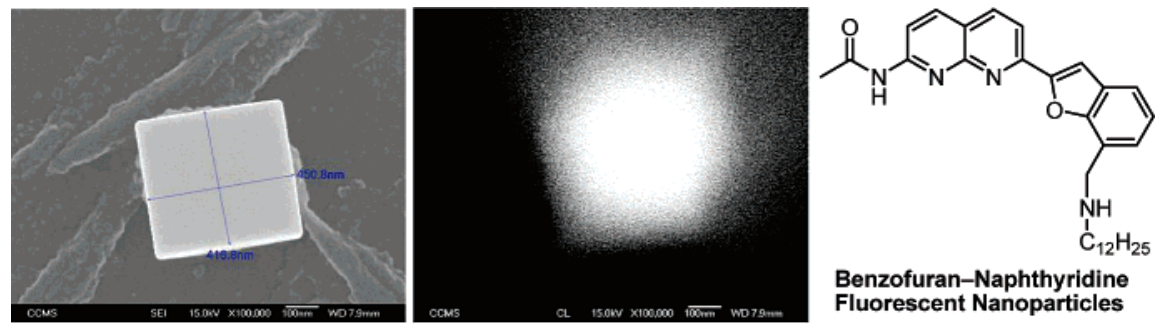

Benzofuran-Naphthyridine Fluorescent Nanoparticles

Enthynyl-linked benzofuran-naphthyridine compounds show high-yield fluorescence with solvatochromic properties. One of the compounds, ABAN, has successfully formed fluorescent organic nanoparticles (FONs), for which the photophysical properties such as the spectral features and intensity are remarkably different from those at the molecular level (solution) and in bulk material. The results are tentatively rationalized by the FONs inducing coplanarization of the benzofuran-naphthyridine molecule to extend its effective conjugation length and hence increase the oscillator strength.

It has been shown that 2-acetamino-1,8-naphthyridine (AN) derivatives bind via triple hydrogen bondings with guanine $(\mathrm{G})^{1}$ preferably over other nitrogenous bases of adenine, cytosine, thymine, and uracil. This property of $\mathrm{AN}-\mathrm{G}$ complexation has been demonstrated in supramolecular chemistry, ${ }^{1}$ HPLC separation, ${ }^{2}$ molecular sensing, ${ }^{3}$ and mapping of the guanine sequence in DNA. ${ }^{4}$

As for our continuous efforts in the development of molecular sensors having the core structure of naphthyridine, ${ }^{5}$ we intended to prepare 2-acetamido-7-(3-formyl-2-hydroxy-

\footnotetext{
Department of Chemistry, National Taiwan University.

$\doteqdot$ Genomics Research Center, Academia Sinica.

$\S$ The Center for Condensed Matter Sciences, National Taiwan University.

(1) (a) Murray, T. J.; Zimmerman, S. C. J. Am. Chem. Soc. 1992, 114, 4010-4011. (b) Corbin, P. S.; Zimmerman, S. C.; Thiessen, P. A.; Hawryluk, N. A.; Murray, T. J. J. Am. Chem. Soc. 2001, 123, 1047510488. (c) Park, T.; Zimmerman, S. C.; Nakashima, S. J. Am. Chem. Soc. $\mathbf{2 0 0 5}, 127,6520-6521$.
}

phenyl)ethynyl-1,8-naphthyridine (compound $\mathbf{X}$ ) via the Sonogashira coupling reaction ${ }^{5}$ of 2-acetamido-8-chloro-1,8naphthyridine ${ }^{1 \mathrm{~b}}$ with3-ethynyl-2-hydroxybenzaldehyde(Scheme 1). However, the desired compound $\mathbf{X}$ was not obtained, and instead, the benzofuran-naphthyridine linked compound $\mathbf{4}$

(2) Feibush, B.; Saha, M.; Onan, K.; Karger, B.; Giese, R. J. Am. Chem Soc. 1987, 109, 7531-7533

(3) Hamilton, A. D.; Pant, N. Chem. Commun. 1988, 765-766.

(4) (a) Nakatani, K.; Sando, S.; Saito, I. J. Am. Chem. Soc. 2000, 122, 2172-2177. (b) Yoshimoto, K.; Nishizawa, S.; Minagawa, M.; Teramae, N. J. Am. Chem. Soc. 2003, 125, 8982-8983. (c) Tok, J. B.-H.; Bi, L.; Saenz, M. Bioorg. Med. Chem. Lett. 2005, 15, 827-831. (d) Peng, T.; Murase, T.; Goto, Y.; Kobori, A.; Nakatani, K. Bioorg. Med. Chem. Lett. 2005, 15, 259-262

(5) (a) Liao, J.-H.; Chen, C.-T.; Chou, H.-C.; Cheng, C.-C.; Chou, P.T.; Fang, J.-M.; Slanina, Z.; Chow, T. J. Org. Lett. 2002, 4, 3107-3110. (b) Fang, J.-M.; Selvi, S.; Liao, J.-H.; Slanina, Z.; Chen, C.-T.; Chou, P.T. J. Am. Chem. Soc. 2004, 126, 3559-3566. (c) Huang, J.-H.; Wen, W.H.; Sun, Y.-Y.; Chou, P.-T.; Fang, J.-M. J. Org. Chem. 2005, 70, 58275832. 
Scheme 1. Synthesis of the Benzofuran-Naphthyridine Linked Compounds BAN, FBAN, HBAN, and ABAN
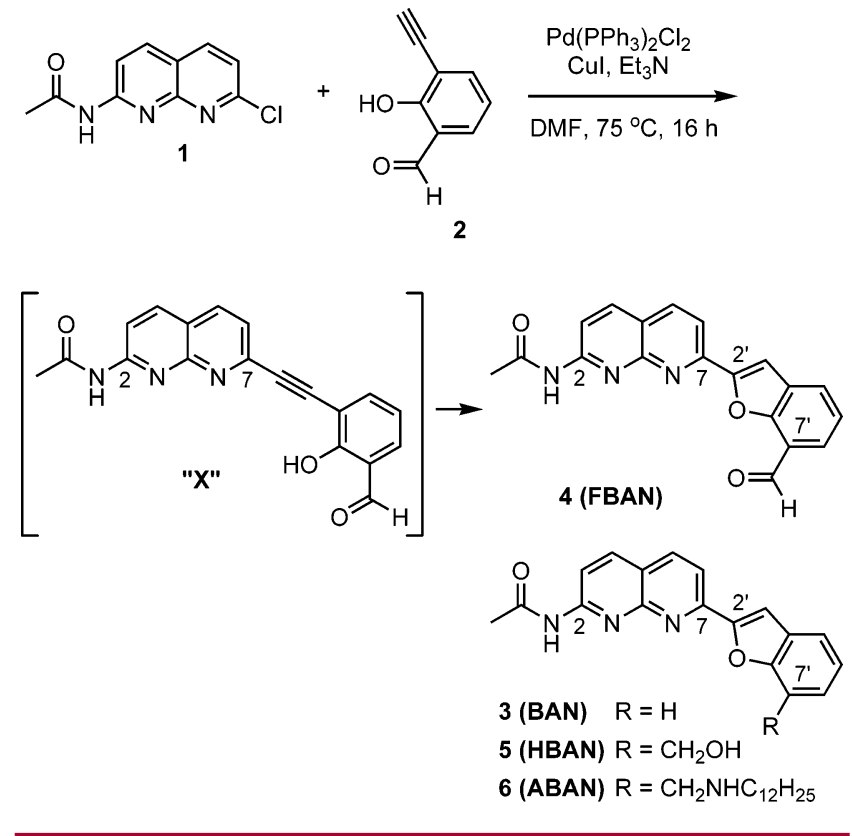

(FBAN) was isolated in $46 \%$ yield. FBAN was presumably derived from the cyclization of the putative intermediate $\mathbf{X}$ via an intramolecular nucleophilic addition of phenolate to the triple bond under the reaction conditions using CuI, Pd$\left(\mathrm{PPh}_{3}\right)_{2} \mathrm{Cl}_{2}$, and $\mathrm{Et}_{3} \mathrm{~N}$ as the promoters. ${ }^{6}$

The Sonogashira coupling reaction with 2-ethynylphenol underwent in a manner similar to that to give 2-acetamido7-(benzofuran-2-yl)-1,8-naphthyridine (BAN, 3) in 53\% yield. Using $\mathrm{NaBH}(\mathrm{OAc})_{3}$ as the reducing agent, FBAN was reduced to give the $7^{\prime}$-hydroxymethyl analogue 5 (HBAN, $78 \%$ yield). The reductive amination of FBAN with laurylamine and $\mathrm{NaBH}(\mathrm{OAc})_{3}$ afforded the $7^{\prime}$-(dodecylamino)methyl analogue 6 (ABAN, 64\% yield).

The heterocycle-linked naphthyridine compounds have been found to have important biological properties such as antibacterials, herbicides, TGF- $\beta$ inhibitors, GABA ligands, and the ligands for nicotinic acetylcholine receptors. ${ }^{7}$ As 2-phenylbenzofuran is known to be a highly fluorescent compound in toluene solution, the benzofuran-naphthyridine linked molecules BAN, FBAN, HBAN, and ABAN may also exhibit interesting spectroscopic properties, especially via changing their conformations under various conditions (vide infra).

Compounds BAN, FBAN, HBAN, and ABAN displayed similar absorption spectra. The absorption maxima appeared

(6) (a) Kabalka, G. W.; Wang, L.; Pagni, R. M. Tetrahedron 2001, 57, 8017-8028. (b) Hiroya, K.; Itoh, S.; Sakamoto, T. Tetrahedron 2005, 61, $10958-10964$.

(7) (a) Mogilaiah, K.; Sreenivasulu, B. Indian J. Chem., B: Org. Chem. Med. Chem. 1982, 21, 479-480. (b) Bratz, M.; Meyer, N.; Koenig, H.; Walter, H.; Gerber, M.; Westphalen, K.-O. Ger. Offen. 1995, 26 pp. (c) Carling, W. R.; Mitchinson, A.; Russell, M. G. N.; Street, L. J. PCT Int. Appl. 2003, 110 pp. (d) Peters, D.; Olsen, G. M.; Nielsen, E. O.; Jorgensen, T. D.; Ahring, P. K. PCT Int. Appl. 2004, 50 pp. (e) Shimizu, K.; Shimizu, T.; Kawakami, K.; Nakoji, M.; Sakai, T. PCT Int. Appl. 2005, 461 pp. at $\sim 360$ and $\sim 378 \mathrm{~nm}$ in various organic solvents (EtOAc, THF, $\mathrm{CH}_{2} \mathrm{Cl}_{2}, \mathrm{EtOH}, \mathrm{MeOH}$, and $\mathrm{CH}_{3} \mathrm{CN}$ ) without the influence of the $7^{\prime}$-substituent $\left(\mathrm{CHO}, \mathrm{CH}_{2} \mathrm{OH}\right.$, or $\mathrm{CH}_{2}$ $\mathrm{NHC}_{12} \mathrm{H}_{25}$ ) on the benzofuran ring. In contrast, the emission spectra of the benzofuran-naphthyridine linked molecules were solvent sensitive. As the polarity of the solvent increased, the fluorescence peak underwent a bathochromic shift. For example, BAN showed the emission maxima at $400,403,405$, and $415 \mathrm{~nm}$, respectively, in the solutions of EtOAc, THF, $\mathrm{CH}_{2} \mathrm{Cl}_{2}$, and $\mathrm{MeCN}$. In protic solvents, a slight blue shift of peak wavelength, $411 \mathrm{~nm}$ in EtOH and $413 \mathrm{~nm}$ in $\mathrm{MeOH}$ compared with $415 \mathrm{~nm}$ in $\mathrm{MeCN}$, was observed despite the fact that the polarity scale is larger or smaller than that in $\mathrm{MeCN}$ (see the Supporting Information). ${ }^{8 \mathrm{~b}}$ The result might be attributable to the external hydrogen-bonding interactions of a protic solvent with the solute. The fluorescence of ABAN also displayed red shifts as the polarity of aprotic solvents increased, e.g., the emission maxima occurring at 401 and $408 \mathrm{~nm}$ in EtOAc and $\mathrm{MeCN}$, respectively. The quantum yields of BAN and ABAN in EtOAc solutions were determined to be 0.72 and 0.18 , respectively, using 7-diethylamino-4-methylcoumarin (coumarin 1) as the standard. The presence of the electron-donating amino group in ABAN might cause the lower fluorescence quantum yield in comparison with BAN. Given the absorption spectral insensitivity to the substituent at the 7-benzofuran site, it is plausible that the two chromophores, i.e., benzofuran and naphthyridine rings, might be mutually orthogonal at the ground state, whereas the benzofuran-naphthyridine linked molecules might undergo conformational changes, such that the intramolecular charge transfer, in part, may take place at the excited state to account for the solvatochromic emissions. ${ }^{8}$

We also investigated the photophysical properties of the benzofuran-naphthyridine linked molecules in $\mathrm{H}_{2} \mathrm{O}$-THF solutions. Although the UV-vis absorption spectra of BAN and HBAN remained unchanged, their emission maxima shifted constantly to longer wavelengths as the content of $\mathrm{H}_{2} \mathrm{O}$ increased (Table 1). Though the fluorescence bathochromic shifts of FBAN and ABAN were less obvious, the fluorescence intensity increased remarkably in $\mathrm{H}_{2} \mathrm{O}-\mathrm{THF}$ solutions with appropriate fractions of water (Table 1 and Figure 1).

It is thus interesting to study the origins of such unusual fluorescence properties in aqueous solution. The observation of a hypsochromic shift in $\mathrm{MeOH}$ and $\mathrm{EtOH}$ (vide supra) led us to conclude that the bathochromic shift caused by the water hydrogen-bonding effect is highly improper. Alternatively, the increasing fluorescence bathochromic shifts of the benzofuran-naphthyridine molecules might be attributable to the conformational change for an effective extended conjugation when their solubility decreased in the media with higher fractions of water. ${ }^{8}$ Likewise, because of the slight change of viscosity in various $\mathrm{H}_{2} \mathrm{O} / \mathrm{THF}$ ratios as well as the polarity insensitive fluorescence yield in nonaqueous

(8) (a) Grabowski, Z. R.; Rotkiewicz, K.; Rettig, W. Chem. Rev. 2003, 103, 3899-4031. (b) Lakowicz, J. R. Principles of Fluorescence Spectroscopy, 2nd ed.; Kluwer: New York, 1999; p 188. 
Table 1. Emission Maxima and Relative Intensity (Arbitrary Units) of the Benzofuran-Naphthyridine Linked Molecules in $\mathrm{H}_{2} \mathrm{O} / \mathrm{THF}$ Solutions $\left(1 \times 10^{-5} \mathrm{M}\right)$

\begin{tabular}{cccll}
\hline & $\begin{array}{c}\text { BAN } \\
\lambda_{\max } / \mathrm{nm} \\
(\text { rel }\end{array}$ & $\begin{array}{c}\text { FBAN } \\
\lambda_{\max } / \mathrm{nm} \\
(\text { rel } \\
\mathrm{H}_{2} \mathrm{O} / \mathrm{THF} \\
\text { v/v ratio }\end{array}$ & $\begin{array}{c}\text { HBAN } \\
\lambda_{\max } / \mathrm{nm} \\
\text { (rel }\end{array}$ & $\begin{array}{c}\text { ABAN } \\
\lambda_{\max } / \mathrm{nm} \\
(\mathrm{rel}\end{array}$ \\
\hline $0: 100$ & $403(1)$ & $404(1)$ & $406(1)$ & $405(1.67)$ \\
$10: 90$ & $411(1.21)$ & $409(4.61)$ & $416(1.16)$ & $409(1)$ \\
$20: 80$ & $414(1.16)$ & $410(5.54)$ & $418(1.19)$ & $410(1.33)$ \\
$30: 70$ & $416(1.19)$ & $409(5.68)$ & $418(1.19)$ & $410(2.33)$ \\
$40: 60$ & $418(1.14)$ & $410(5.82)$ & $421(1.16)$ & $410(2.00)$ \\
$50: 50$ & $418(1.16)$ & $409(6.25)$ & $425(1.25)$ & $409(4.33)$ \\
$60: 40$ & $424(1.16)$ & $409(10.8)$ & $426(1.30)$ & $412(5.00)$ \\
$70: 30$ & $426(1.16)$ & $409(10.9)$ & $430(1.48)$ & $411(12.7)$ \\
$80: 20$ & $430(1.14)$ & $412(9.72)$ & $435(1.33)$ & $412(13.7)$ \\
$90: 10$ & $431(1.12)$ & $412(8.87)$ & $435(1.29)$ & N.A. ${ }^{a}$
\end{tabular}

${ }^{a}$ Not available because of the interference of some microcrystals. The cathodoluminescence spectrum of ABAN nanoparticles showed an emission peak wavelength at $\sim 420 \mathrm{~nm}$.

solution, the enhancement of fluorescence intensity could not be explained simply by the change of polarity and viscosity in solution or by the inhibition of, e.g., the photoinduced electron-transfer process in ABAN (or FBAN).

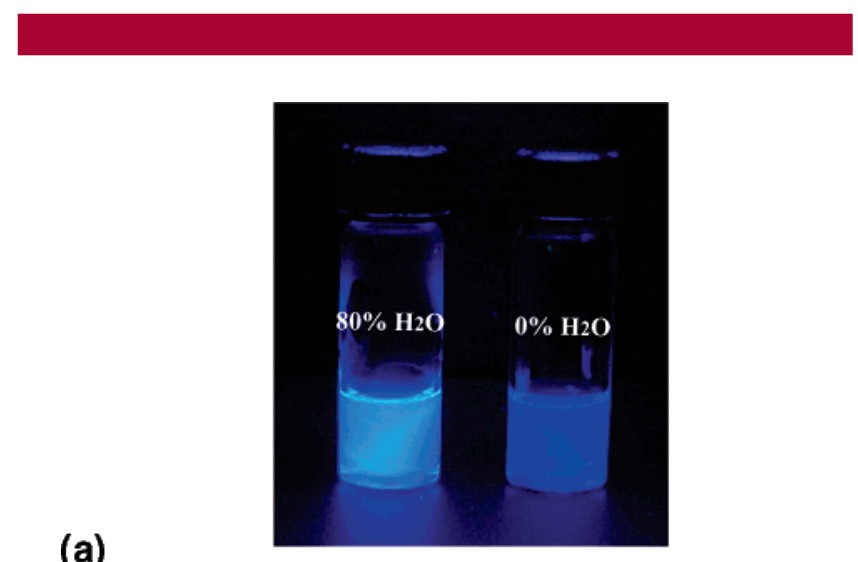

(a)

(b)

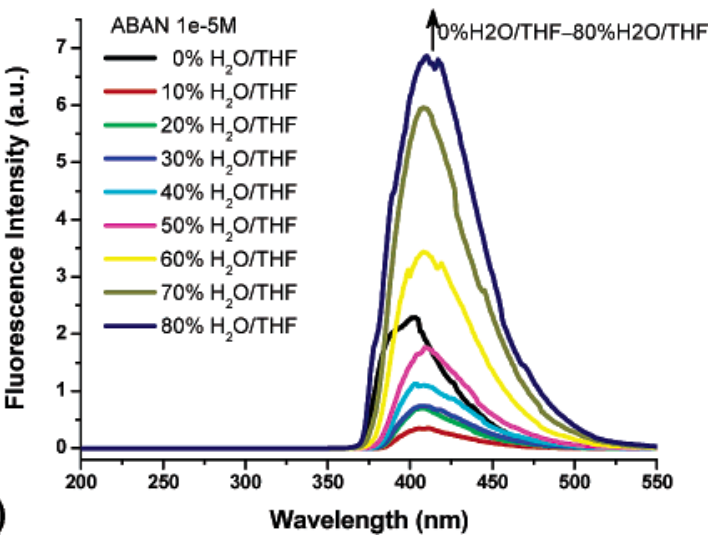

Figure 1. Fluorescence properties of compound 6 (ABAN) in $\mathrm{H}_{2} \mathrm{O}-\mathrm{THF}$ solution. (a) Enhanced fluorescence of compound 6 (ABAN) in $\mathrm{H}_{2} \mathrm{O}-\mathrm{THF}$ solution ( $\left./ \mathrm{v}, 4: 1\right)$ with excitation at 378 nm. (b) Emission spectra of ABAN in $\mathrm{H}_{2} \mathrm{O}-\mathrm{THF}$ solutions $(1 \times$ $\left.10^{-5} \mathrm{M}\right)$.
We thus speculated that nanoparticles of FBAN and ABAN might form in $\mathrm{H}_{2} \mathrm{O}$-THF solutions to account for the remarkable luminescence enhancement, even though the dispersions were transparent and macroscopically homogeneous with no precipitation.

In recent years, quite a few fluorescent organic nanoparticles (FONs) have been prepared. ${ }^{9}$ With their unique optical behavior, FONs are potentially utilized in optoelectronic devices and sensors. For example, FONs of perylene ${ }^{9 \mathrm{a}, \mathrm{b}}$ and pyrazoline $^{9 c, i}$ are reported to exhibit the size-dependent fluorescent properties differing from those of bulk samples. Upon formation of nanoparticles, the FONs of arylethynyl derivatives, pentaphenylsilole, ${ }^{\mathrm{e}}$ and 1-cyano-trans-1,2-bis(4'-methylbiphenyl)ethylene ${ }^{9 \mathrm{~g}}$ give enhanced fluorescence, rather than the generally observed fluorescence quenching in the solid state of planar $\pi$-conjugated compounds. ${ }^{10}$ The decrease of fluorescence is often attributed to the intermolecular vibronic interactions in the solid state to induce nonradiative deactivation processes, whereas the emission enhancement is presumably due to the effects of intramolecular planarization and a specific intermolecular aggregation in the solid state.

In this study, the fluorescent ABAN nanoparticles were readily obtained in various sizes by the reprecipitation method, ${ }^{9}$ although the nanoparticles of BAN, FBAN, and HBAN appeared to be more difficult to form at this stage. In a typical preparation protocol of the ABAN nanoparticles, both a good solvent (THF) and a nonsolvent (deionized $\mathrm{H}_{2} \mathrm{O}$ ) were filtered by a membrane of $0.2 \mu \mathrm{M}$ porosity, and then water was added slowly $(2.7 \mathrm{~mL} / \mathrm{h})$ via syringe to the THF solution of ABAN with vigorous stirring $(1200 \mathrm{rpm})$ at room temperature. With this method, the ABAN nanoparticles were prepared in the shapes of a sphere, a cuboid, and a hexagonal pillar with various sizes $(30-200 \mathrm{~nm})$ under different conditions, mainly controlled by the fraction of water and the final concentration of the nanoparticle dispersion. The ABAN nanoparticle dispersion appeared to be stable on standing at room temperature for $24 \mathrm{~h}$.

The sizes of nanoparticles were determined by the scanning electron microscopy (SEM) and dynamic light scattering (DLS) imagings. The particle size appeared to increase with higher fractions of water. For example, the nanoparticles prepared by adding water to the THF solution of ABAN at a concentration of $1 \times 10^{-5} \mathrm{M}$ showed the average particle

(9) (a) Nalwa, H. S.; Kasai, H.; Okada, S.; Oikawa, H.; Matsuda, H. Kakuta, A.; Mukoh, A.; Nakanishi, H. Adv. Mater. 1993, 5, 758-760. (b) Kasai, H.; Kamatani, H.; Yoshikawa, Y.; Okada, S.; Oikawa, H.; Watanabe, A.; Itoh, O.; Nakanishi, H. Chem. Lett. 1997, 26, 1181-1182. (c) Fu, H. B.; Yao, J. N. J. Am. Chem. Soc. 2001, 123, 1434-1439. (d) Levitus, M.; Schmieder, K.; Ricks, H.; Shimizu, K. D.; Bunz, U. H. F.; Garcia-Garibay, M. A. J. Am. Chem. Soc. 2001, 123, 4259-4265. (e) Luo, J.; Xie, Z.; Lam, J. W. Y.; Cheng, L.; Chen, H.; Qiu, C.; Kwok, H. S.; Zhan, X.; Liu, Y.; Zhu, D.; Tang, B. Z. Chem. Commun. 2001, 1740-1741. (f) Gong, X.; Milic, T.; Xu, C.; Batteas, J. D.; Drain, C. M. J. Am. Chem. Soc. 2002 124, 14290-14291. (g) An, B. K.; Kwon, S. K.; Jung, S. D.; Park, S. Y. J. Am. Chem. Soc. 2002, 124, 14410-14415. (h) Sun, F.; Zhang, F.; Zhao, F.; Zhou, X.; Pu, S. Chem. Phys. Lett. 2003, 380, 206-212. (i) Xiao, D.; Xi, L.; Yang, W.; Fu, H.; Shuai, Z.; Fang, Y.; Yao, J. J. Am. Chem. Soc. 2003, 125, 6740-6745. (j) Li, S.; He, L.; Xiong, F.; Li, Yi.; Yang, G. J. Phys. Chem. B 2004, 108, 10887-10892. (k) Xi, L.; Fu, H.; Yang, W.; Yao, J. Chem. Commun. 2005, 492-494. 1970 .

10) Birks, J. B. In Photophysics of Aromatic Moelcules; Wiley: London, 

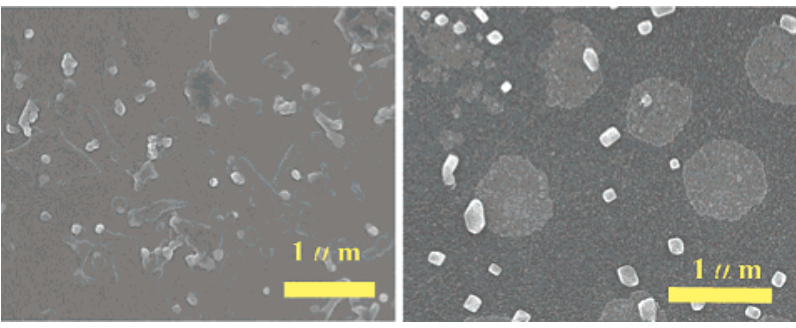

Figure 2. SEM images of ABAN nanoparticles. Typical SEM images of ABAN nanoparticles prepared in $1 \times 10^{-5} \mathrm{M} \mathrm{H}_{2} \mathrm{O}-$ THF solution with v/v of 4:1 (left) and 9:1 (right).

sizes of $137 \pm 15$ and $189 \pm 20 \mathrm{~nm}$, respectively, in 4:1 and 9:1 $\mathrm{H}_{2} \mathrm{O} / \mathrm{THF}$ solutions (Figure 2). It was noted that the conventional reprecipitation method by adding the THF solution of ABAN to water gave the nanoparticles with large sizes $(\sim 500 \mathrm{~nm})$ in a $4: 1 \mathrm{H}_{2} \mathrm{O} / \mathrm{THF}$ solution at $1 \times 10^{-5} \mathrm{M}$. Vigorous stirring $(1200 \mathrm{rpm})$ was required to obtain the ABAN nanoparticles in uniform size; mild stirring (300 rpm) resulted in a large size distribution of nanoparticles (30$200 \mathrm{~nm}$ ). Preparation at a high concentration tended to give large nanoparticles; i.e., the more concentrated solution of ABAN tended to form the larger particles. The ABAN nanoparticles were best prepared at room temperature (25$\left.30{ }^{\circ} \mathrm{C}\right)$; no satisfactory nanoparticle formation occurred at lower or elevated temperature $\left(0\right.$ or $\left.50^{\circ} \mathrm{C}\right)$.

We also selected several ABAN nanoparticles to perform the cathodoluminescence (CL) experiments. ${ }^{11} \mathrm{~A}$ representative CL image was shown in Figure 3, which clearly indicated the desired luminescence under electronic excitation. The CL spectrum showed an emission peak wavelength at $\sim 420 \mathrm{~nm}$, close to that of $\mathrm{ABAN}$ dispersion in 9:1 $\mathrm{H}_{2} \mathrm{O} /$ THF. In comparison, the luminescence of the ABAN nanoparticle and its dispersion in aqueous media occurred at a longer wavelength with remarkably enhanced intensity compared to that of ABAN in pure THF. Accordingly, the ABAN nanoparticle was presumably formed as a $J$-type aggregation with a head-to-tail arrangement of the transition dipole in $\mathrm{H}_{2} \mathrm{O}$ - THF media. ${ }^{9}$ The aggregation would induce coplanarization of the benzofuran-naphthyridine molecule to extend its effective conjugation length and increase the oscillator strength. The former can be verified by its characteristic bathochromic shift in the absorption/emission spectra. ${ }^{12}$ The latter viewpoint can be supported by the dynamic approaches, in which the observed fluorescence lifetime increased by a factor of 2.4 from $1.42 \mathrm{~ns}$ (in pure THF solution) to $3.46 \mathrm{~ns}$ (for the FONs prepared from 9:1 $\mathrm{H}_{2} \mathrm{O}-\mathrm{THF}$ solution), whereas the fluorescence intensity was enhanced by as much as $\sim 8.5$-fold.

The spectral properties of ABAN nanoparticles were distinct from those of bulk material. For example, the film

(11) (a) Pfefferkorn, G.; Broecker, W.; Hastenrath, M. Scanning Electron Microsc. 1980, 251-258. (b) Dhara, S.; Datta, A.; Hsu, C. W.; Wu, C. T.; Shen, C. H.; Lan, Z. H.; Chen, K. H.; Chen, L. C.; Wang, Y. L.; Chen, C. C. Appl. Phys. Lett. 2004, 84, 5473-5475.

(12) Levitus, M.; Schmieder, K.; Ricks, H.; Shimizu, K. D.; Bunz, U. H. F.; Garcia-Garibay, M. A. J. Am. Chem. Soc. 2001, 123, 4259-4265.
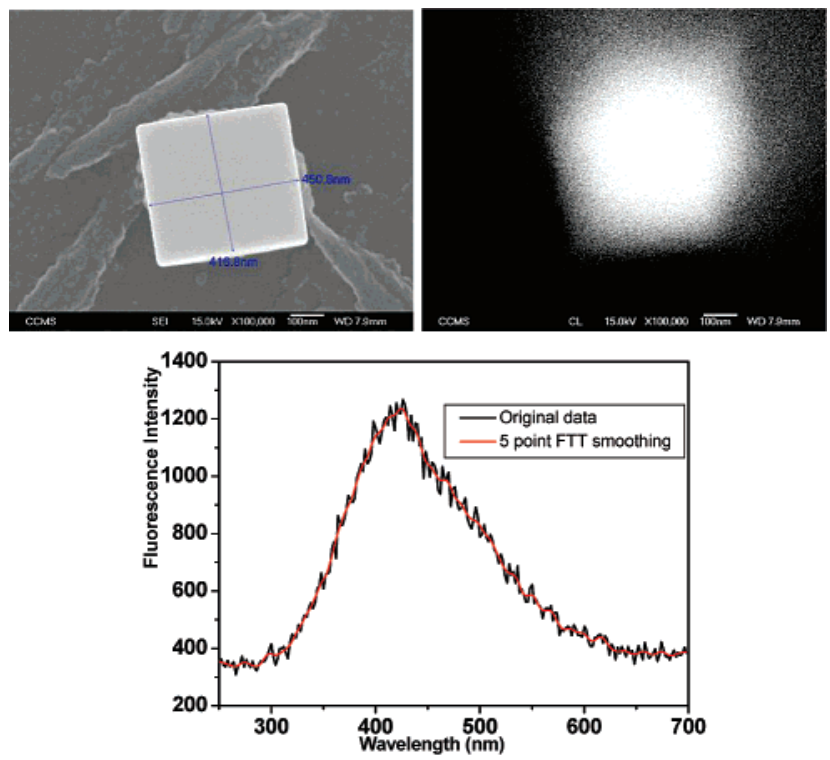

Figure 3. Cathodoluminescence of the ABAN nanocrystal. (a) SEM image of a selected nanocrystal with the size of $417 \times 452$ $\mathrm{nm}$ obtained by slow addition of deionized water to THF solution of $\mathrm{ABAN}$ at $5 \times 10^{-5} \mathrm{M}\left(9: 1 \mathrm{H}_{2} \mathrm{O} / \mathrm{THF}\right)$. (b) Cathodoluminescence image of the ABAN nanocrystal obtained from the emission at 360 nm. (c) The cathodoluminescence spectrum shows $\lambda_{\max } \approx 420$ $\mathrm{nm}$ : the original curve is black in color, and the 5 point FTT smoothing curve is red in color.

of ABAN in the solid state exhibited a broad fluorescence spectrum with the emission maximum occurring at $504 \mathrm{~nm}$ (see the Supporting Information), which is much more red shifted than the ABAN nanoparticles. The broad emission spectrum may indicate a strong random aggregation effect in the bulk material.

In summary, benzofuran-naphthyridine linked compounds were serendipitously obtained via the Sonogashira coupling reaction between 2-acetamido-8-chloro-1,8-naphthyridine and 3 -ethynylphenols, followed by an intramolecular nucleophilic addition of the intermediate phenolates to the triple bond. These compounds all show high-yield fluorescence with solvatochromic properties. One of the compounds, ABAN, has successfully formed FONs, for which the photophysical properties such as the spectral features and intensity are remarkably different from those at the molecular level (solution). Because of the versatility of functionalization, the design and synthesis of benzofuran - naphthyridine analogues suited for molecular recognition are feasible. This, in combination with their possible structural uniqueness in forming FONs, should spark a broad spectrum of interest in the fields of physical organics, organic devices, and FONs.

Acknowledgment. We thank the National Science Council for financial support.

Supporting Information Available: Details of experimental procedures and NMR, UV-vis, and fluorescence spectra. This material is available free of charge via the Internet at http://pubs.acs.org.

OL061293P 